\title{
Occurrence of exercise induced bronchospasm in elite runners: dependence on atopy and exposure to cold air and pollen
}

\author{
Ilkka J Helenius, Heikki O Tikkanen, Tari Haahtela
}

\begin{abstract}
Objectives-To study factors affecting the occurrence of exercise induced bronchospasm (EIB) in elite runners.

Methods-Fifty eight elite runners, $79 \%$ of them belonging to Finnish national teams, volunteered. The athletes answered a questionnaire on respiratory symptoms. Skin prick tests were used to investigate atopy, and spirometry to examine lung function at rest and after an exercise challenge test (ECT) at subzero temperature in the winter and after a similar ECT in the summer at the end of the birch pollen season.

Results-Definitive EIB (a post-exercise reduction of $10 \%$ or more in forced expiratory volume in one second $\left(\mathrm{FEV}_{1}\right)$ ) was observed in five $(9 \%)$ of the 58 runners. A subgroup consisting of 19 nonatopic symptom-free runners with no family history of asthma was used to establish a normal range for post-exercise reduction in $\mathrm{FEV}_{1}$. When this group's mean exercise induced change in $F_{1}$ minus 2 SDs (a reduction of $6.5 \%$ or more in FEV ${ }_{1}$ ) was taken as the lower limit of the reference range, $15(26 \%)$ of the runners had probable EIB in either the winter or the pollen season. The occurrence of probable EIB depended on atopy (odds ratio increased with number of positive skin prick test reactions, $p<0.05$ ). Nine $(22 \%)$ of the 41 runners, challenged in both the winter and the pollen season, had probable EIB only in the winter, and three $(7 \%)$ had it only in the pollen season. Only one runner (2\%) had EIB in both tests.

Conclusions-Mild EIB is common in Finnish elite runners and is strongly associated with atopy. Seasonal variability affects the occurrence of EIB, and thus exercise testing should be performed in both cold winter air and the pollen season to detect EIB in elite runners.

(Br F Sports Med 1998;32:125-129)
\end{abstract}

Keywords: exercise induced bronchospasm; atopy; seasonal variability; athletes

Exercise induced bronchospasm (EIB) in athletes has been observed by several investigators, who have reported widely different prevalences. In the 1984 United States Olympic team, $11 \%$ of the athletes had EIB. ${ }^{1}$ Of 983 new intercollegiate athletes, $2.8 \%$ had EIB on treadmill exercise challenge tests (ECTs). ${ }^{2}$ Of
1530 Swiss athletes, $1.4 \%$ had a decrease of $10 \%$ or more in their forced expiratory volume in one second $\left(\mathrm{FEV}_{1}\right)$ after an ECT indoors. ${ }^{3}$ Rupp et $a l^{4}$ studied 166 college athletes, and observed that a combination of symptom history and spirometry was not sufficient for the adequate detection of EIB in high school athletes. However, most studies on the occurrence of EIB in athletes have been carried out only in athletes complaining of exercise induced respiratory symptoms, and do not reflect the true occurrence of EIB in elite athletes.

EIB can be modified using different air temperature and humidity conditions during the ECT. ${ }^{5}$ Bronchospasm in connection with exercise is enhanced by cold dry air ${ }^{6}$ and in pollen allergic asthmatics by pollen. ${ }^{78}$ In Finland, athletes train under varying climatic conditions. Inhalation of cold dry air in winter during exercise has been shown to provoke bronchospasm in susceptible runners. ${ }^{9}$ In the spring and summer, athletes are exposed to pollen. ${ }^{10}$ To clarify the effects of such seasonal factors on EIB in elite athletes, we subjected an unselected population of elite runners to ECTs in the winter at subzero temperature and in the pollen season.

\section{Methods}

SUBJECTS

Fifty eight unselected runners volunteered for the study, 46 of whom belonged to Finnish national teams. In eight (14\%) asthma had been diagnosed, in all cases the diagnosis having been made during the runner's active sports career. Four of these asthmatics inhaled steroid regularly; one inhaled sodium cromoglycate, one inhaled nedocromil sodium, and all inhaled $\beta_{2}$ agonists as needed. The runners had competed for a mean of 9.8 (range 2-20) years. Their main events ranged from $400 \mathrm{~m}$ to the marathon. They had run a mean distance of 4170 (range 2000-8500) $\mathrm{km}$ in the previous year. Table 1 characterises the study group further. All subjects gave their informed written consent. The protocol was approved by the local ethics committee.

\section{STUDY DESIGN}

The first part of the study was carried out in February-March 1994. It included a winter ECT at the Finnish Sports Institute (Vierumäki, Finland) (table 2) and further studies at the Helsinki University Central Hospital, where the runners answered a questionnaire, were interviewed by one of the authors (I H), and were subjected to skin prick tests (SPTs) 
Table 1 Characteristics of the study population of 58 elite runners

\begin{tabular}{ll}
\hline Characteristic & Value \\
\hline Women/men & $15 / 43$ \\
Mean (SD) age (years) & $24.0(5.6)$ \\
Members of national teams, No (\%) & $46(79)$ \\
History of exercise induced bronchial symptoms, No (\%) & $18(31)$ \\
Mean (SD) FVC & $5.28(0.98)$ \\
$\quad$ In litres & $101.4(10.4)$ \\
As \% of predicted & \\
Mean (SD) FEV & $4.59(0.86)$ \\
In litres & $100.7(10.6)$ \\
As \% of predicted & $11.11(2.00)$ \\
Mean (SD) PEF & $109.6(13.2)$ \\
$\quad$ In litres/second & \\
As \% of predicted & \\
\hline
\end{tabular}

${ }^{\star}$ Reference values were those of Viljanen. ${ }^{12}$

FVC, forced vital capacity; $\mathrm{FEV}_{1}$, forced expiratory volume in one second; PEF, peak expiratory flow.

and a resting spirometric examination. The second part of the study, in May-June 1994, at the Finnish Sports Institute, included a pollen season ECT. Of the 58 runners studied, 54 performed the ECT in the winter, 46 in the pollen season, and 41 performed both tests.

The birch pollen counts used to identify the birch pollen season were from Kangasala, 100 $\mathrm{km}$ west of Vierumäki, indicating roughly the pollen situation in Southern Finland, where all the runners were living. The pollen season ECTs were performed soon after the highest pollen counts (fig 1); pretest exposure is an even better predictor of risk of EIB than the actual exposure during the $\mathrm{ECT}^{8}{ }^{\mathrm{A}}$ A volumetric seven day Burkard sampler (Burkard Manufacturing Co.) was used to trap pollen. Samples were analysed at the Aerobiology Unit, University of Turku. Figure 1 shows weekly pollen counts and timing of the ECTs. ${ }^{11}$

\section{EXERCISE CHALLENGE TESTS}

The ECT consisted of running $2000 \mathrm{~m}$ outdoors on the cross country track of the Finnish Sports Institute. To achieve uniform exercise and ventilatory responses, runners were instructed to raise their heart rates in a controlled manner. They carried on the wrist a heart rate meter and recorder (Sport Tester TM PE 3000, Polar Electro Ky, Kempele, Finland), from which they could see their heart rate.

The athletes did no warm up exercises or training before the ECT on the test day. Inhaled $\beta_{2}$ agonists and cromones were withheld for 12 hours before the ECT, but inhaled steroids were used unrestricted. During the first $500 \mathrm{~m}$ of the ECT, the athletes accelerated, raising their heart rates to $85 \%$ of their personal maximum, which was calculated from the formula $205-0.5 \times$ age. The runners ran

Table 2 Climatic conditions, pre-exercise forced expiratory volume in one second (FEV, and performance of the runners in the winter and pollen season exercise challenge test. Values are means (SD)

\begin{tabular}{lll}
\hline Parameter & Winter & Pollen season \\
\hline Air temperature $\left({ }^{\circ} \mathrm{C}\right)$ & $-6.6(4.9)$ & $8.3(4.0)$ \\
Water content $\left(\mathrm{g} / \mathrm{m}^{3}\right)$ & $2.8(1.2)$ & $5.9(1.6)$ \\
Pre-exercise $\mathrm{FEV}_{1}$ & $4.81(0.83)$ & $4.78(0.76)$ \\
$\quad$ In litres & $104.2(12.1)$ & $102.4(10.6)$ \\
$\quad \%$ of predicted & $176(10)$ & $174(8)$ \\
Maximal heart rate (beats $/ \mathrm{min})$ & 7 min $16 \mathrm{~s}(50 \mathrm{~s})$ & 6 min $49 \mathrm{~s}(47 \mathrm{~s})$ \\
Running time & & \\
\hline
\end{tabular}

${ }^{\star}$ Reference values were those of Viljanen. ${ }^{12}$

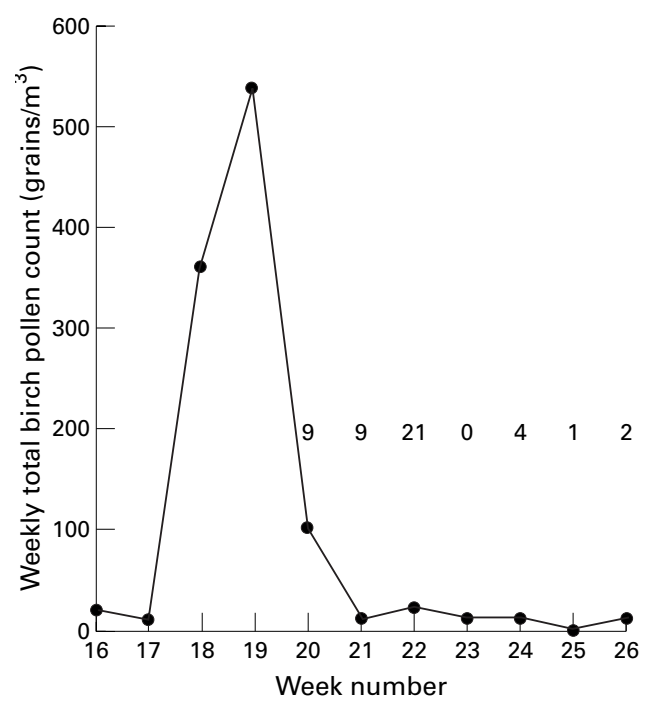

Figure 1 Total weekly birch pollen counts preceding exercise challenge tests in the pollen season. ${ }^{11}$ Numbers indicate the number of exercise challenge tests performed in each week.

the remaining $1500 \mathrm{~m}$ without changing the running velocity reached.

$\mathrm{FEV}_{1}$ was measured using a pocket sized spirometer (Vitalograph Escort, Vitalograph Ltd, Buckingham, UK), which was calibrated daily. Measurements were made indoors at a temperature of $20-22^{\circ} \mathrm{C}$ and a relative humidity of $50-65 \%$. Subjects wore nose clips. Measurements were made immediately before and at 4, 10 and 20 minutes after exercise. Each time, in a standing position, the runners made three spirometry efforts, and the best result of the three was used. To measure EIB, the maximal change in $\mathrm{FEV}_{1}$ was calculated as $100 \% \times$ ((post-exercise $\mathrm{FEV}_{1}$ - pre-exercise $\mathrm{FEV}_{1}$ )/preexercise $\mathrm{FEV}_{1}$ ). As a measure of bronchospasm we used the maximal value of the percentage change in $\mathrm{FEV}_{1}$ (positive or negative).

All runners had $\mathrm{FEV}_{1}$ values within the reference (normal) range $^{12}$ before the ECT (table 2). The mean outdoor temperature during the ECT was $-6.6^{\circ} \mathrm{C}$ in the winter and $+8.3^{\circ} \mathrm{C}$ in the pollen season. The mean running time was 37 seconds longer $(\mathrm{p}<0.01)$ in the winter than in the pollen season; this was due to the slippery conditions encountered in the winter. Mean maximal heart rates were similar on both occasions.

Definitive EIB was defined as a $10 \%$ reduction or more in post-exercise $\mathrm{FEV}_{1}$ compared with pre-exercise $\mathrm{FEV}_{1}$ values. ${ }^{13}$ Nineteen nonatopic symptom-free runners with no family history of asthma participated in the ECT in the winter or in the pollen season (12 of them participated in both tests). We used the results of this subpopulation to establish a reference (normal) range. ${ }^{9}{ }^{14}$ The mean maximal exercise induced change in $\mathrm{FEV}_{1}$ minus $2 \mathrm{SDs}$ was taken as the lower limit of the reference range. A reduction in $\mathrm{FEV}_{1}$ greater than $6.5 \%$ was outside the reference range and considered probable EIB. 


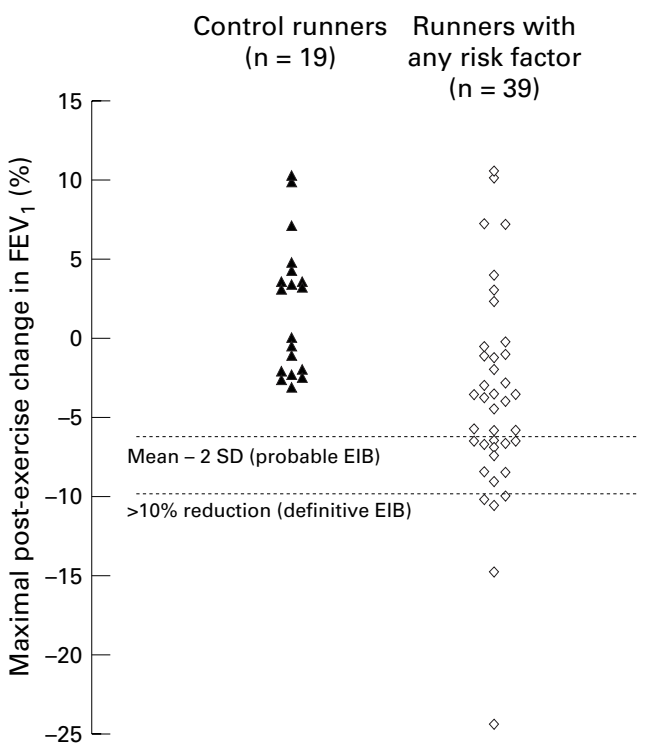

Figure 2 Maximal post-exercise changes in forced expiratory volume in one second (FEV) in either the winter or pollen season exercise challenge test in the control runners and in runners with any risk factor (exercise induced bronchial symptoms, family history of asthma, atopy).

SPIROMETRY AT REST

Resting flow volume spirometry was carried out with a Medikro 909 spirometer (Medikro Oy, Kuopio, Finland). Subjects wore nose clips. Three reasonably reproducible efforts, with less than 5\% difference between the two best ones, were required. ${ }^{15} \mathrm{FEV}_{1}$, forced vital capacity, and peak expiratory flow were measured, and values for the best effort were used in each case. Values were expressed as percentages of reference (predicted) values for adult Finns. $^{12}$

SPTS AND ATOPY

SPTs were carried out with ten common air borne allergens and positive (histamine dihydrochloride, $10 \mathrm{mg} / \mathrm{ml}$ ) and negative (solvent) control solutions from ALK (Soluprick SQ, 10 histamine equivalent pricks (HEP); Allergologisk Laboratorium, Horsholm, Denmark). The allergens were as follows: birch, timothy, meadow fescue, and mugwort pollen; horse, cat, dog, and cow dander; the mite Dermatophagoides pteronyssinus; and mould spores of Cladosporium herbarum. A subject was classified as atopic if any allergen caused a weal $3 \mathrm{~mm}$ or larger in diameter than negative controls. Runners who had positive skin tests to birch pollen and symptoms of rhinoconjunctivitis in the birch pollen season were considered allergic to birch pollen.

Table 3 Odds ratios (OR) and their 95\% confidence interval (95\% CI) for the occurrence of probable exercise induced bronchospasm according to the number of positive skin prick test (SPT) reactions

\begin{tabular}{lll}
\hline $\begin{array}{l}\text { Number of positive SPT } \\
\text { reactions }\end{array}$ & OR & $95 \%$ CI \\
\hline 0 & 1 & \\
$1-2$ & 3.13 & 0.63 to 15.45 \\
$3-4$ & 4.17 & 0.80 to 21.64 \\
$\geqslant 5$ & 4.69 & 0.75 to $29.27^{\star}$ \\
\hline
\end{tabular}

$\star \chi^{2}$ test for trend, $\mathrm{p}<0.05$.
RESPIRATORY SYMPTOM QUESTIONNAIRE

The questionnaire was based on the recommendations of Ferris ${ }^{16}$ and was used in our previous study. ${ }^{17}$ Questions concerned the occurrence of asthma, allergy, asthma medication, family history of asthma, symptoms of hay fever, and exercise induced bronchial symptoms. The latter were considered to occur if symptoms (shortness of breath, wheeze, cough) had been observed repeatedly during the last year. Answers to the self administered questionnaire were confirmed in interviews.

\section{STATISTICAL ANALYSIS}

Means (SD) are given. To examine differences between groups, we used the Mann-Whitney U test, the Wilcoxon signed rank sum test, the McNemar test, and the $\chi^{2}$ test for trend. For correlations, Spearman's rank correlation test was used. Two-tailed p values below 0.05 were considered significant.

\section{Results}

Resting spirometry results were within the reference (normal) range ${ }^{12}$ for all runners (table 1). Eighteen (31\%) of the runners had a history of exercise induced bronchial symptoms. Twenty nine runners (50\%) were atopic as judged by SPT. Ten of the atopics were allergic to birch pollen.

Definitive EIB was observed in five (9\%) of the 58 runners either in the winter or in the pollen season ECT (a maximal post-exercise reduction in $\mathrm{FEV}_{1}$ of $10 \%$ or more) (fig 2). Fifteen $(26 \%)$ of the 58 runners had probable EIB either in the winter or in the pollen season ECT (a maximal post-exercise reduction in $\mathrm{FEV}_{1}$ of $6.5 \%$ or more) (fig 2). Eleven (19\%) had bronchospasm in the winter and five (9\%) in the pollen season. The mean (SD) maximal post-exercise change in $\mathrm{FEV}_{1}$ in those with probable EIB was -9.6 (4.7)\% or -490 (270) $\mathrm{ml}$ in absolute terms. Of the fifteen runners with EIB, two had a history of previous physician diagnosed asthma and regularly used antiinflammatory medication (one inhaled steroid, the other inhaled nedocromil). All fifteen runners with EIB had at least one risk factor for asthma: $11(73 \%)$ were atopic, six (40\%) had a history of exercise induced bronchial symptoms, and two (13\%) had a first degree relative with asthma.

Atopic runners had a larger maximal postexercise fall in $\mathrm{FEV}_{1}$ than non-atopic runners $(\mathrm{p}<0.005)$. The number of positive SPT reactions correlated with the maximal postexercise fall in $\mathrm{FEV}_{1}(r=-0.42, \mathrm{p}<0.005)$. The odds for the occurrence of EIB increased with the number of positive SPT reactions $(p<0.05)$ (table 3).

Runners with a previous history of exercise induced bronchial symptoms had a larger maximal post-exercise fall in $\mathrm{FEV}_{1}$ than runners with no such history $(\mathrm{p}<0.05)$.

Forty one runners participated in the ECT in both the winter and pollen season. Only one $(2 \%)$ had EIB on both occasions. In nine (22\%) runners, probable EIB was observed only in the winter, and in three $(7 \%)$ only in the 
pollen season. Of the ten runners with birch pollen allergy, two had probable EIB in the winter, two in the pollen season, and six had no bronchospasm. Of the 31 non-birch pollen allergic runners, seven had probable EIB only in the winter, one only in the pollen season, and one had EIB on both occasions.

\section{Discussion}

We found definitive EIB in $9 \%$ of unselected Finnish elite runners. However, a much larger proportion of the runners $(26 \%)$ have EIB, if a more sensitive approach is used. A large proportion of the runners with EIB were unaware of the condition. ECTs were carried out in both the winter and the pollen season; in most cases EIB occurred only in one season. Atopy was strongly associated with EIB, and the risk of EIB also increased with the number of positive SPT reactions.

VALIDITY OF THE DATA

The elite runners participated in carefully controlled outdoor ECTs, consisting of a $2000 \mathrm{~m}$ run on the cross country track of the Finnish Sports Institute. Our study may underestimate the magnitude of EIB, because four of the runners studied used regularly inhaled steroids, which have been shown to decrease exercise induced pulmonary changes. ${ }^{18} 19$

No generally accepted reference (normal) range for exercise induced pulmonary changes in athletes exists. EIB was defined in two ways. Firstly, a cut off point of reduction of $10 \%$ or more in $\mathrm{FEV}_{1}$ was used according to the European Respiratory Society's recommendations. ${ }^{13}$ Secondly, we used the mean maximal postexercise change in $\mathrm{FEV}_{1}$ minus 2 SDs obtained for the 19 runners with the lowest risk of bronchoconstriction (non-atopic, symptom-free, no family history of asthma). A maximal reduction of $6.5 \%$ or more in $\mathrm{FEV}_{1}$ was out of range and considered probable EIB. We have used this approach before, ${ }^{9}{ }^{14}$ and it also has been found useful in studies on children with atopy or chronic lung disease. ${ }^{20-22}$

COMPARISON WITH PREVIOUS FINDINGS

Exercise testing for bronchospasm has been rarely performed in normal training conditions in elite athletes. Previously, Mannix et $a l^{23}$ performed lung function measurements in figure skaters after four or five minutes of strenuous skating routines. They observed EIB in 35\% of the 124 skaters studied when using a cut off point of $10 \%$ for maximal post-exercise fall in $\mathrm{FEV}_{1}$. This is comparable with the $19 \%$ prevalence that we observed in runners in cold winter air.

Like Karjalainen et $a l{ }^{8}$ we found that the exercise response of the runners who were not allergic to birch pollen attenuated in the warmer and more humid pollen season compared with the cold dry winter weather. Of the runners who were allergic to birch pollen, two, who showed a normal response in the winter, exhibited an abnormal response in the pollen season. This indicates seasonal variability of EIB, but the athlete population studied was too small to draw any definite conclusions. Kar- jalainen et $a l^{8}$ observed a non-significant increase in EIB during the pollen season compared with winter weather in asthmatics allergic to birch pollen. However, variation in EIB cannot be totally explained by environmental conditions such as air temperature, humidity, and allergen exposure. ${ }^{24}$

We have previously reported that $17 \%$ of long distance runners and $8 \%$ of speed and power athletes have been diagnosed as having asthma. ${ }^{17} \mathrm{~A}$ much larger proportion of the athletes reported symptoms compatible with EIB. However, as shown now by us, $60 \%$ of the athletes with probable EIB had no previous indications of asthma. These findings as well as those of Mannix et $a^{23}$ suggest that all competitive athletes should be tested for the possibility of EIB under conditions similar to those encountered during training and competition. Owing to the marked variability of EIB, exercise testing in cold winter weather and in the pollen season may be particularly relevant in pollen allergic athletes.

It would be interesting to know the prevalence with which EIB occurs in healthy non-athletes undertaking exercise under conditions resembling those studied here. We did not include a control group in the present study, because the tests performed on the athletes would be difficult to carry out on sedentary control subjects. Some conclusions can be drawn from studies on young adults in compulsory military service: a $6 \%$ prevalence rate of EIB has been found. ${ }^{25} 26$

As shown also by Rupp et $a l,{ }^{4}$ athletes with EIB can by no means always be identified using history of symptoms and resting spirometry alone. In a clinical situation, evaluation of the risk for EIB in athletes is most important. Thus history of exercise induced bronchial symptoms gave $40 \%$ of runners with EIB in the present study, and asking for a family history of asthma gave $13 \%$ more. However, use of SPTs for atopy identified $47 \%$ more runners with EIB. Thus SPTs for atopy are obviously helpful when evaluating the risk.

ATOPY AND SPORTS

The present study confirms our previous findings that atopic allergy is a significant risk factor for EIB in elite athletes, even if they have no other indications of asthma. ${ }^{9}$ In a recent study, Brutsche et $a l^{25}$ found a significant relation between EIB and the presence of allergen specific IgE in healthy soldiers subjected to exercise tests after the main pollen season. Djukanovic et $a l^{27}$ have suggested that mild bronchial mucosal inflammation exists in atopic non-asthmatic patients, the condition being intermediate between that seen in asthmatics and healthy persons. Natural pollen exposure in pollen sensitive asthmatics affects $\mathrm{T}$ cell and mast cell function in the bronchial mucosa. ${ }^{28}$ Long exposure to pollen allergens during training and competition, especially in runners sensitised to pollen allergens, may be manifested as an abnormal response to exercise as found in this study.

We found that a relatively high proportion of the runners $(50 \%)$ were atopic, and, in the 
subgroup of runners with bronchoconstriction, $73 \%$ were atopic, although the group was unselected. In swimmers and also in other athletes participating in endurance events, the occurrence of atopy assessed by SPT appears to be higher than in the general population. ${ }^{29} 30$ This can be explained by the lengthy exposure to air borne allergens during endurance training in the spring and summer. ${ }^{10}{ }^{17}$ The association between atopy and EIB may therefore explain why asthma and EIB are common in highly trained athletes.

In conclusion, $26 \%$ of the elite runners studied had mild EIB either in the winter or the pollen season ECT. A large proportion of the runners with EIB were unaware of having the condition. Seasonal variability affected the occurrence of EIB. Therefore we suggest that all highly trained athletes should be tested for the possibility of EIB in the winter, and pollen allergic athletes also in the pollen season.

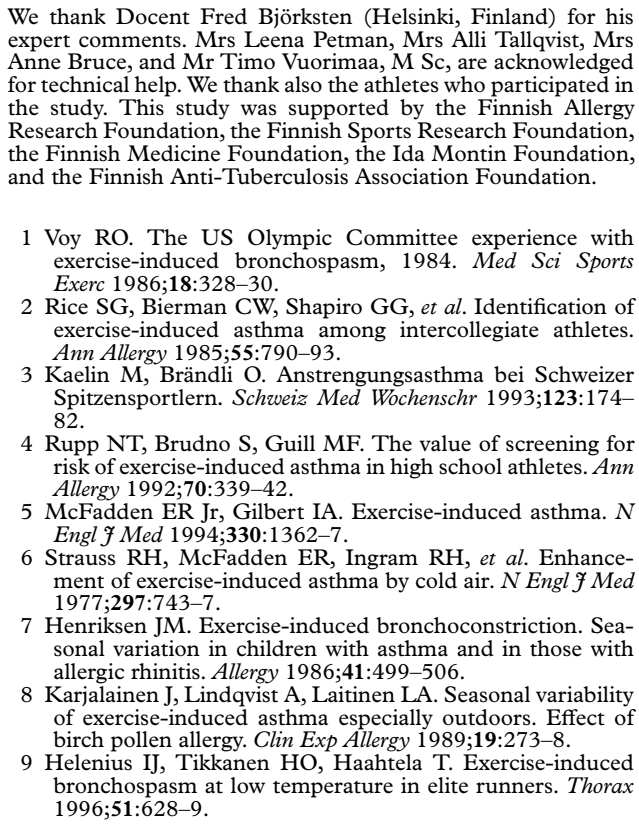

We thank Docent Fred Björksten (Helsinki, Finland) for his expert comments. Mrs Leena Petman, Mrs Alli Tallqvist, Mrs Anne Bruce, and Mr Timo Vuorimaa, M Sc, are acknowledged Anne Bruce, and Mr Timo Vuorimaa, M Sc, are acknowledged for technical help. We thank also the athletes who participated in the study. This study was supported by the Finnish Allergy
Research Foundation, the Finnish Sports Research Foundation, the Finnish Medicine Foundation, the Ida Montin Foundation, the Finnish Medicine Foundation, the Ida Montin Foundation,
and the Finnish Anti-Tuberculosis Association Foundation.

1 Voy RO. The US Olympic Committee experience with exercise-induced bronchospasm, 1984. Med Sci Sports Exerc 1986;18:328-30.

2 Rice SG, Bierman CW, Shapiro GG, et al. Identification of exercise-induced asthma among intercollegiate athletes. Ann Allergy 1985;55:790-93.

3 Kaelin M, Brändli O. Anstrengungsasthma bei Schweizer Spitzensportlern. Schweiz Med Wochenschr 1993;123:17482.

4 Rupp NT, Brudno S, Guill MF. The value of screening for risk of exercise-induced asthma in high school athletes. Ann Allergy 1992;70:339-42.

$5 \mathrm{McF}$ adden ER Jr, Gilbert IA. Exercise-induced asthma. $N$ Engl F Med 1994;330:1362-7.

6 Strauss RH, McFadden ER, Ingram RH, et al. Enhancement of exercise-induced asthma by cold air. $N$ Engl f Med ment of exercise-

7 Henriksen JM. Exercise-induced bronchoconstriction. Seasonal variation in children with asthma and in those with allergic rhinitis. Allergy 1986;41:499-506.

8 Karjalainen J, Lindqvist A, Laitinen LA. Seasonal variability of exercise-induced asthma especially outdoors. Effect of birch pollen allergy. Clin Exp Allergy 1989;19:273-8.

9 Helenius IJ, Tikkanen HO, Haahtela T. Exercise-induced bronchospasm at low temperature in elite runners. Thorax 1996;51:628-9.

10 Tikkanen HO, Helenius I. Asthma in runners [letter]. BM7 1994;309:1087.

11 The Finnish Aerobiology Group. Pollen and spore statistics for 1994. The Finnish Pollen Bulletin 1994;19(suppl):1-53.

12 Viljanen A. Reference values for spirometric, pulmonary diffusing capacity and body plethysmographic studies. Scand f Clin Lab Invest 1982;42(suppl 159):1-50.

13 Sterk PJ, Fabbri LM, Quanjer PH, et al. Airway responsiveness. Standardized challenge testing with pharmacological, physical and sensitizing stimuli in adults. Eur Respir f 1993; 6(suppl 16):53-83.

14 Tikkanen H, Helenius I, Haahtela T. Pulmonary functions of healthy elite runners in winter and pollen season outdoor running test [abstract]. Med Sci Sports Exerc 1996; 28(suppl):S90.

15 American Thoracic Society. Standardization of spirometry: 1987 update. American Review of Respiratory Disease 1987; 136:1285-98

16 Ferris BG. Epidemiology standardization project. American Review of Respiratory Disease 1978;118(suppl):7-53.

17 Helenius IJ, Tikkanen HO, Haahtela T. Association between type of training and risk of asthma in elite athletes. Thorax 1997;52:157-60.

18 Henriksen JM, Dahl R. Effects of inhaled budesonide alone and in combination with low-dose terbutaline in children with exercise-induced asthma. American Review Respiratory Disease 1983;128:993-7.

19 Henriksen JM. Effect of inhalation of corticosteroids on exercise-induced asthma: randomised double-blind crossover study of budesonide in asthmatic children. BMF 1985; 291:248-9.

20 Godfrey S, Springer C, Noviski N, et al. Exercise but not metacholine differentiates asthma from chronic lung disease in children. Thorax 1991;46:488-92.

21 Custovic A, Arifhodzic N, Robinson A, et al. Exercise testing revisited: the response to exercise in normal and atopic children. Chest 1994;105:1127-32.

22 Avital A, Springer C, Bar-Yishay E, et al. Adenosine, metacholine, and exercise challenges in children with asthma or paediatric chronic obstructive pulmonary disease. Thorax 1995;50:511-16.

23 Mannix ET, Farber MO, Palange P, et al. Exercise-induced asthma in figure skaters. Chest 1996;109:312-15.

24 Henriksen JM. Reproducibility of exercise-induced asthma in children. Allergy 1986;41:225-31.

25 Brutsche M, Britschgi D, Dayer E, et al. Exercise-induced bronchospasm (EIB) in relation to seasonal and perennial specific IgE in young adults. Allergy 1995;50:905-9.

26 O'Donnell AE, Fling CJ. Exercise-induced airflow obstruction in a healthy military population. Chest 1993;103:7424.

27 Djukanovic R, Lai CKW, Wilson JW, et al. Bronchial mucosal manifestations of atopy: a comparison of markers of inflammation between atopic asthmatics, atopic nonasthmatics and healthy controls. Eur Respir F 1992;5:538-44.

28 Djukanovic R, Feather I, Gratziou C, et al. Effect of natural pollen allergen exposure during the grass pollen season on airways inflammatory cells and asthma symptoms. Thorax 1996;51:575-81.

29 Helenius I, Tikkanen H, Haahtela T. Allergic disorders in elite athletes [abstract]. Allergy 1996;51(suppl):S63.

30 Zwick H, Popp W, Budik G, et al. Increased sensitization to aeroallergens in competitive swimmers. Lung 1990;168 $111-15$.

\section{Commentary}

This Finnish trial set out to study the factors that affect recurrence of exercise induced bronchospasm in their elite national teams and whether they include cold dry air in the winter and birch pollen in the summer. A group of elite runners volunteered and were studied with skin tests and exercise challenge tests at subzero temperatures and during the pollen season. The results were analysed to find out the incidence of exercise induced asthma. Exercise induced asthma was defined in this study in two ways, firstly as a reduction of $10 \%$ or more in $\mathrm{FEV}_{1}$ after exercise, and secondly using the mean maximal post-exercise change in $\mathrm{FEV}_{1}$ minus two standard deviations of a number of runners with lowest risk of bronchoconstriction.

The outcome was interesting in that the number of subjects who suffered from exercise induced bronchospasm within the group was much higher than has been reported in other trials, but, as the authors point out, many athletes are unaware that they suffer from bronchospasm, and it may be that these athletes think that their particular response to exercise is normal.

It would be interesting to compare these 58 runners who volunteered with 58 controls, but, as the authors state, this is technically very difficult to do in view of the fact that controls are not able to run at the speeds that elite Finnish runners can maintain. 